\title{
Development of Emergency Response Team Technical Competency (ER2TC) Assessment Tool for Offshore Process Safety
}

\author{
Wen Khai Lim ${ }^{1}$, Risza Rusli ${ }^{1}$, Azizul Buang ${ }^{1}$, Taram Satiraksa Wan Abdullah ${ }^{2}$ \\ ${ }^{1}$ Chemical Engineering Department, Universiti Teknologi PETRONAS, Malaysia \\ ${ }^{2}$ HSE Department, Vestigo Petroleum Sdn Bhd, Malaysia \\ *Corresponding author: risza@utp.edu.my
}

\author{
Article History \\ Received: January 29, 2021 Received in revised form: March 31, 2021 Accepted: April 05, 2021 \\ Published Online: June 30, 2021
}

\begin{abstract}
The importance in identifying safety critical task in high-risk industries for competence assessment is greatly emphasised to ensure the personnel is well equipped with high level of competence and assurance in certain safety critical tasks. Lack of competency had resulted in various accidents in oil and gas industry. Failure in escape, evacuation, and rescue (EER) operation in history has led to tragic consequences associated with high number of fatalities, such as Alexander $\mathrm{L}$. Kielland platform collapse, Piper Alpha disaster and tragedy of Ocean Ranger. Although competency assessment is widely implemented in offshore industry, accident still occur which indicates that reliable competency assessment is highly essential. In this research, a technical competency assessment tool is developed to assess the technical skills of each individual in emergency response team during EER activities. Case studies are selected to evaluate the designed Emergency Response Team Technical Competency (ER2TC) assessment tool where a range of different inputs and parameters are designed and tested on the designed tool. Analysis is conducted to identify how the overall output is affected by the uncertainty from the designed tool's input and discover the impact of potential errors in the tool towards the output generated from the tool. The ER2TC assessment tool overcomes personal subjectivity and biasness of assessors, thus, producing reusable and reliable tool for decision makers in the evaluation of candidates. This tool has also implemented stricter assessing criteria to evaluate the performance of candidates in EER activities. This is seen as necessary due to the critical nature and the must to ensure the successful for EER operations as any failure could potentially results in loss of lives. Thus, this ER2TC assessment tool has indeed sufficient to assess the technical skills of personnel in ensuring the success of EER operations in offshore installations.
\end{abstract}

Keywords: EER; emergency response team; offshore; process safety; safety critical task; technical competency assessment.

\subsection{INTRODUCTION}

In the 1988 Piper Alpha disaster, although Claymore platform and Tartan platform had already aware of the incident that took place in Piper Alpha, oil and gas were still continuously supplied respectively to Piper Alpha from both neighbouring platforms which further worsen the overall situation, resulted in loss of 167 lives [1]. Such action has raised questions on the level of competency of the key personnel and Offshore Installation Managers (OIMs) of Claymore and Tartan platform.

In April 2010, the Macondo well blowout had caused the loss of 11 human lives. Uncontrollable flow of oil continued to flow out from the well until July 2010 where the well was capped had resulted in severe pollution to the environment and affected thousands of birds and marine lives. According to Deepwater Horizon Study Group formed by members of the Center for Catastrophic Risk Management following this accident, one of the factors that led to Macondo well blowout was lacking in proper selection and training of personnel [2]. 
In the period after the occurrence of Piper Alpha disaster, the dilemma faced by the engineering management was just how truly competency is measured? In previous methodologies, companies send their employees to attend trainings where certificate of attendance was provided and checked the training box only. There was no any additional assessment being conducted to ensure that their employee was actually competent enough to apply the knowledge received in their respective workplace [3]. There is no clear guideline on how to carry out assessment and record for audit and validation in Standard or any related documentation [4]. Unlike competency assessment especially in medical industry, there are clear explanation and standardised guidelines on the method to assess the competency level of candidate [5-8]. In fact, there is great emphasised on the importance in identifying safety critical task in high-risk industries for competence assessment to ensure the personnel is well equipped with high level of competence and assurance in certain safety critical tasks $[9,10]$.

Competency assessment is carried out across different industries and different fields, to ensure that the person in charge is able to reach the standards as anticipated in the employment/job description to execute the tasks within function or occupation. Control of Major Accident Hazard Regulations 1999 (COMAH) was implemented on 1st April 1999, with the purposes to prevent major accidents by dangerous substances and control the consequences to wards human and environment if accidents occurred. Unverified assumptions regarding staff competence are no longer acceptable based on the regulation [11]. In Malaysia, Control of Industrial Major Accident Hazards (CIMAH) Regulations 1996 stated that evidence are required to demonstrate that adequate steps have been taken for the prevention of any major accident or minimise the consequences of the accident to human and environment [12,13]. Arrangement for training persons working on the site must be included in the safety report. According to Malaysia Factories and Machinery Act 1967 (Revised1974) (Acts 139), inexperienced workers are required to be provided with adequate training and supervision [14]. No person are allowed to be employed to deal with any machine or any process unless the person has been fully educated on the danger associates with the work and safety precautions that required to be observed, and either acquires adequate instructions in the work dealing with machine or process or work under adequate supervision where the person responsible for supervision is required to equip with knowledge and experience regarding the machine or process [14].

Competency assessment is emphasised and practised in several other industries such as medical and aviation industry. There is great difference in terms of defining competency when compared to medical surgeons and aircraft pilots. For medical surgeons, they must first qualify as Doctor of medicine. Next, they are required to further continue postgraduate study and go through trainings through positions junior before being qualified as a surgeon [3]. The importance of technical competency assessment in medical industry is recognised [15]. The competency assessment system is study in depth [5-8] and well establish with the purpose to accredit the capabilities of a surgeon was supported, not so much because of the quantity of procedures that performed, but for which the competency that is able to demonstrate for the establishment of a surgical technique, with basic safety and efficacy [16]. As for aviation sector, the requirements for pilot qualification includes a series of training, experience and assessment, which also covers the progression from one grade to another, transfer between different types of aircraft and continuous competence assurance $[3]$.

Observational assessment is the method that is widely used by offshore industry when conducting performance assessment [9]. The references for the trainer to make judgement will be either based on certain process values recorded by simulator during the whole simulation session or referring to the final outcome on whether the task was completed successfully or not [17]. The major issue associate to the final judgement on the assessment conducted is the strong dependent to personal opinions and biasedness of the trainer. In fact, the subjectivity of the final judgement in assessing performance may differ based on the trainers in charge.

As human involvement and intervention is still required even in the fully automated section, either in terms of operation or maintenance, it is clear that the competence level of human involved has direct impact on the controls efficiency. Staff competency is one of the essential focuses in order to ensure the effectiveness of systems, where each of them from managers level down to employee levels are required to equip with sufficient experience, skills and knowledge to control major accident hazards within their responsibilities. It is very clear that competency assessment is not only limited for existing employee but organisations are also required to assess the competency for new hires and contractors [9].

Escape, evacuation, and rescue (EER) from offshore installations is consider as the final line of defence to prevent serious injury and loss of life from hazardous and unsafe incidents, for example extreme harsh weather, well blowouts, loss of containment of subsea pipeline or riser, uncontrolled fire, loss of containment in process facilities and ship collision $[18,19]$. Tragic consequences associated with high number of fatalities are resulted from failure in EER operation in history, such as Alexander L. Kielland platform collapse, Piper Alpha disaster and tragedy of Ocean Ranger $[1,20,21]$.

Industry-based guidelines have stated that operators play an important role in the evacuation preparedness of an offshore installation $[18,22]$. The significance of competency assessment in ensuring the safety and success of operations has been highlighted in different studies [9, 23-25].

The definition of evacuation, escape and rescue are described as follows $[1,22,26]$. The term evacuation is referring to 
the designed procedure to evacuate from offshore installation without entering into the sea directly. Personnel on board of the installation being transported either to vessel, safe offshore site or onshore location are considered success evacuation, which may involve lifeboats, helicopters or bridge-links.

Escape refers to the approach of evacuating the installation during emergency when the evacuation system has failed to operate. This is considered as the final approach to leave the installation where there is no other ways and this may involve in entering into the sea directly. The escape means cover items that assist the personnel to enter the sea, such as ladders, life-rafts and chute systems; and items that enable personnel to float when in the sea such as throw-over liferafts.

Rescue is defined as the process to recover personnel after their evacuation or escape from offshore installation. Rescue also includes rescue survivors near the installation and transfers them to safe location.

Different hazards can cause different potential and speed of escalation, lead to several EER scenarios and subsequently influence the evacuation and escape approach [20]. The following list covers some of the hazards that have could possibly result in EER [18, 27].

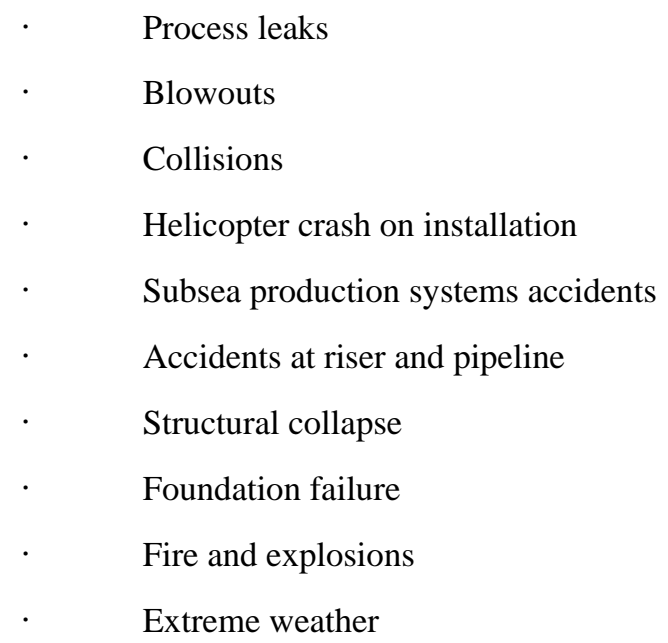

Hierarchical Task Analysis (HTA) has been widely applied as the general technique to examine tasks as this method is capable to outline the main goal and sub-goals and describes their interactions to assist the identification of human errors when executing the tasks [28]. The developments of HTA has been applied and extended to different fields for different purposes such as job aid design, interface design and evaluation, error prediction, and work load assessment [29]. Although HTA is unable to examine every human factors decision without reference other approaches and ideas, however it provides guidance on the evaluation of tasks which contributes great benefits for all the other approaches and ideas [30]. HTA has been applied in diverse industries, for example critical flight tasks for error prediction [31], evaluation on new in-cab information technology used in long freight trains [32], prototypical designs for error identification [33], analyse hydropower plant accidents through combination of HTA with fault tree [34], and complex overhead crane type machines for identification of design deficiencies that potentially contributed to operator's error [35]. In this research, HTA is utilised to organise the input information for the tool.

The aim of this research is to develop a technical competency assessment tool which able to quantify the technical skills assessment of each individual in emergency response team. In the present project, Emergency Response Team Technical Competency (ER2TC) assessment tool is developed.

\subsection{METHODOLOGY}

The ER2TC assessment tool methodology is divided into two sections and delivered in a series of consecutive steps as below. Section 1 describes base template and section 2 describes assessment template.

\subsection{Base Template}

Step 1.1: List down the task steps in sequence and categorised according to the appropriate level as defined in HTA.

Step 1.2: Determine the availability of recovery step if error occurred in that particular task. $\mathrm{R}=0.5$ if recovery step is available, else $\mathrm{R}=1$.

Step 1.3: Define Severity Rating, SR into four categories which are catastrophic, critical, marginal and minor according 
to the severity of consequences. Value is assigned to each category and represents the severity of the consequence, where catastrophic $=27$, critical $=9$, marginal $=3$ and minor $=1$ [36]. The definitions for the four categories are described in Table 1 [37]. With this technique, the worst potential outcome of a specific error can be assigned. In order to determine parameter that is able to reflect the realistic nature of the assessment tool in the case of task failure, two different sets of SR parameters are designed with reference to the metrics as guidance [36], and inserted into the assessment tool to run scenario. The finding is explained in details under section 3.1.1.

Table 1. Classification of the severity of consequences

\begin{tabular}{|l|l|c|}
\hline \multicolumn{1}{|c|}{ Magnitude } & \multicolumn{1}{|c|}{ Description } & SR \\
\hline Catastrophic & Failure may lead to multiple deaths & 27 \\
\hline Critical & $\begin{array}{l}\text { Failure which may cause individual deaths } \\
\text { or severe injuries }\end{array}$ & 9 \\
\hline Marginal & $\begin{array}{l}\text { Failure may cause minor injuries or delays } \\
\text { during an evacuation }\end{array}$ & 3 \\
\hline Minor & Failure not serious enough to cause injury & 1 \\
\hline
\end{tabular}

Step 1.4: Assign value to each of the task step according to sequence. If the sequence of the tasks is planned in order, Sq value is assigned to each of the task step as:

$$
S q=\{n, n-1, \ldots, 2,1\}
$$

Where $\mathrm{n}$ is the total number of tasks in level $\mathrm{i}$.

If certain group of tasks can be planned in any order or simultaneously, Sq value is assigned to that particular group of tasks as:

$$
\text { Sq for simultaneous tasks }=n+1-j, j>1
$$

Where $\mathrm{j}$ is the task step for the group of tasks that can be planned in any order or simultaneously occur.

Step 1.5: Calculate the max score for a particular task. The max score for a particular task, Smax is calculated as:

$$
S \max =S R \times S q \times R
$$

Step 1.6: Calculate the total max score for the tasks from similar level, i. The total max score for all the tasks from similar level, TSmax $_{\mathrm{i}}$ is calculated as:

$$
\operatorname{TSmax}_{i}=\sum \operatorname{Smax}_{i}
$$

Where $\operatorname{Smax}_{\mathrm{i}}$ is the max score for a particular task from the similar level.

\subsection{Assessment Template}

Step 2.1: Fill in the Action column. If the task is carried out accurate and complete, $A=1$, else $A=0$.

Step 2.2: Calculate the score obtained for a particular task. The score obtained for that particular task conducted by candidate, $\mathrm{S}$ is calculated as:

$$
S=A \times S \max
$$

Step 2.3: Calculate the total score obtained for all the tasks from similar level. The total score obtained for all the tasks from similar level, $\mathrm{TS}_{\mathrm{i}}$ is calculated as:

$$
T S_{i}=\sum S_{i}
$$

Where $S_{i}$ is the score obtained for a particular task from the similar level.

If the particular task consist of subtask, 
Step 2.4: Calculate the multiplying factor. The multiplying factor, MF is calculated as:

$$
M F_{i}=T S_{i} \div T \operatorname{Smax}_{i}
$$

Step 2.5: The calculation for the score obtained for a particular task that consist of subtask is revised:

$$
S=A \times \operatorname{Smax} \times M F_{i+1}
$$

Where $\mathrm{MF}_{\mathrm{i}+1}$ is the multiplying factor that is calculated from the subtask one level lower than the particular task.

Step 2.6: Calculate the overall score. The overall score, OS is calculated as:

$$
O S=T S_{1} \div \operatorname{TSmax}_{1} \times 100
$$

Where $\mathrm{TS}_{\mathrm{i}}$ and $\mathrm{TSmax}_{\mathrm{i}}$ are the total score obtained and total max score from the level $\mathrm{i}$. Note that when $\mathrm{i}=1$, $\mathrm{TS}_{1}$ and $\mathrm{TSmax}_{1}$ is the total score obtained and total max score from the top level.

\subsection{RESULTS AND DISCUSSION}

In this research, a case study is selected to evaluate the designed ER2TC assessment tool, extracted from the hierarchical task analysis of evacuation, escape and rescue [37]. The case study selected is ensuring sea worthiness of Totally Enclosed Motor Propelled Survival Craft (TEMPSC), as shown in Figure 1.

In this case study, the assessment is conducted to determine competency level of the emergency response personnel in-charge in ensuring sea worthiness of TEMPSC. These actions are performed before boarding every other on-board personnel to evacuation and abandon offshore installation to safe locations during emergency. The nature of this assessment is critical as there is high potential to jeopardise the successfulness of evacuation to safe area if one of the tasks failed to carry out as intended.

Two different aspects of potential failures are taken into account in ER2TC assessment tool. The first aspect is the criticality of the task related to the possible consequences that will directly impact to the personnel in the TEMPSC if that particular task failed to execute as intended. This aspect is reflected in the value of SR in ER2TC. For example, every personnel have already boarded into TEMPSC but sea worthiness of TEMPSC is not ensured by personnel in-charge. When the TEMPSC has launched onto the sea surface, the engine is unable to start. This not only delayed the time to bring every personnel inside the TEMPSC to safe area, but in the worst case scenario may result in multiple loss of lifes. The second aspect is the criticality of the task related to the continuance of tasks after. In some of the tasks listed in HTA as shown in Figure 1, the tasks are planned to perform in order, which means that those group of tasks can only be carried out according to sequence. For example, task 3.5 Perform engine checks and task 3.6 Engage full reverse neutral RPM. According to the plan, task 3.5 has to be executed successfully before task 3.6 can be carried out. This is because if the engine is not started or unable to start, the personnel in-charge unable to trial engage the TEMPSC move forward, reverse, neutral and increase the engine RPM to increase speed during preparation. Therefore, it shows that for tasks that required performing in sequence, the prior task carries higher criticality as compare to latter task.

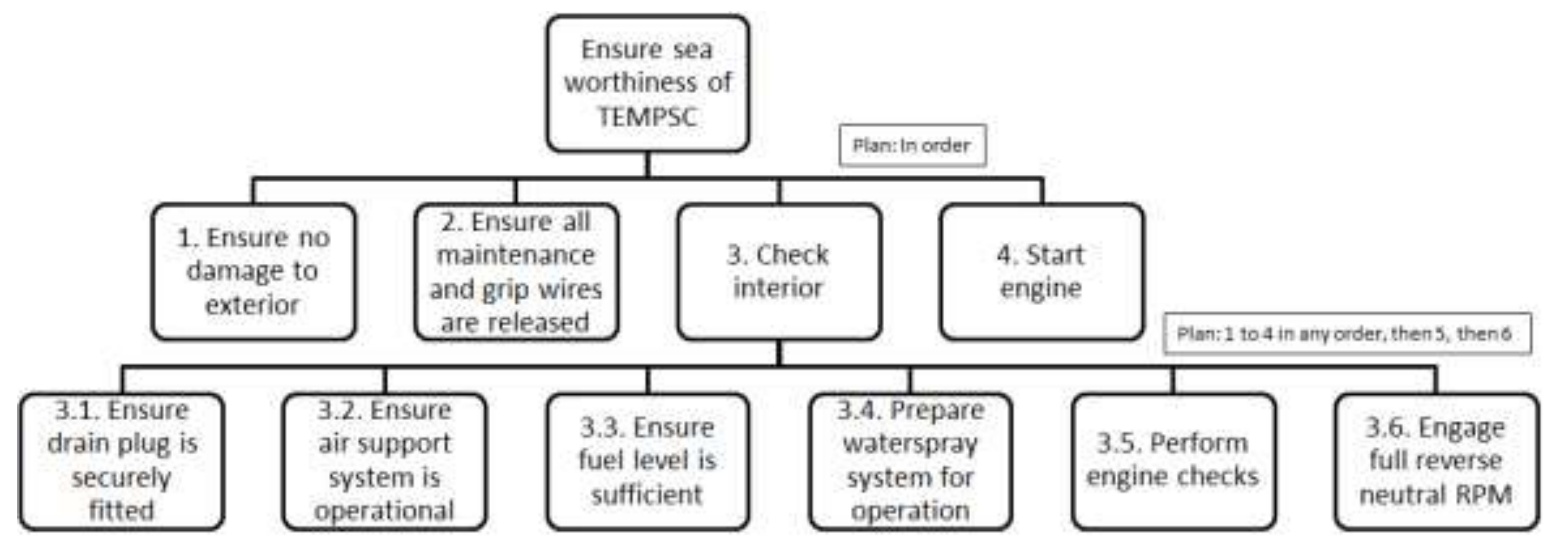

Figure 1. HTA for ensure sea worthiness of TEMPSC 


\subsection{Sensitivity analysis}

This ER2TC assessment tool relies on a few input parameters, where each of them is subjected to some variability or uncertainty. Sensitivity analysis is conducted to identify how the overall output is affected by the uncertainty from the tool's inputs. Besides, this also helps to discover the impact of potential errors in the designed tool towards the output generated from the tool. A range of different inputs and parameters are designed and tested on the tool.

\subsubsection{Severity Rating}

The factors that influence the overall score the most are the severity rating especially those tasks with high severity rating. This is expected as the value assigned for high severity rating is much higher as compared to other parameters. The task sequence arrangement is also important as the task sequence contributed the 2 nd highest value in the calculation. The other parameters in the tool make smaller difference as compared to severity rating and task sequence. If the severity rating is adjusted to factor of 1 as demonstrated in Table 2, the differences between each severity rating are not significance.

Table 2. Case study with SR in factor of 1 and factor of 3

\begin{tabular}{|c|l|c|c|}
\hline Level & \multicolumn{1}{|c|}{ Task Step } & SR (Factor of 1) & SR (Factor of 3) \\
\hline 1 st & $\begin{array}{l}\text { Ensure sea worthiness of } \\
\text { TEMPSC }\end{array}$ & 4 & 27 \\
\hline
\end{tabular}

\begin{tabular}{|l|l|c|c|}
\hline \multirow{2}{*}{ 2nd } & $\begin{array}{l}1 \text { Ensure no damage to } \\
\text { exterior }\end{array}$ & 4 & 27 \\
\cline { 2 - 3 } & $\begin{array}{l}\text { 2 Ensure all maintenance } \\
\text { and gripe wires are released }\end{array}$ & 2 & 3 \\
\cline { 2 - 4 } & 3 Check interior & 3 & 9 \\
\cline { 2 - 4 } & 4 Start engine & 2 & 3 \\
\hline
\end{tabular}

\begin{tabular}{|l|l|c|c|}
\hline 3 3rd & $\begin{array}{l}3.1 \quad \text { Ensure drain plug is } \\
\text { securely fitted }\end{array}$ & 1 & 1 \\
\hline $\begin{array}{l}3.2 \text { Ensure air support } \\
\text { system is operational }\end{array}$ & 2 & 3 \\
\hline $\begin{array}{l}3.3 \text { Ensure fuel level is } \\
\text { sufficient }\end{array}$ & 2 & 3 \\
\hline $\begin{array}{l}3.4 \text { Prepare waterspray } \\
\text { system for operation }\end{array}$ & 2 & 3 \\
\hline $\begin{array}{l}3.5 \text { Perform engine checks } \\
\text { 3.6 Engage full reverse } \\
\text { neutral RPM }\end{array}$ & 3 & 9 \\
\hline
\end{tabular}

The value of the tasks that would result in catastrophic consequences is not much different compare to the tasks that would only cause minor consequences. In the end, failure to complete low severity task would impact the overall score almost as much as the failure to complete high severity task. However, if the severity rating is adjusted to factor of 3 , the differences between each severity rating are more significance and would provide greater impact to the OS. The impact of SR towards OS in factor of 3 is $70.8 \%$ higher than SR in factor of 1, which is more desirable to highlight SR as the main parameter in the tool. Therefore, it is necessary to set the severity rating in factor of 3 to demonstrate the greater difference between low severity task and high severity task in order to emphasise on the importance of task severity in EER activities.

\subsubsection{Task Sequence}

The sequence of task has also been tested with two different sets of parameters, Set A and Set B. Set A is assigned with value of 1 for all the task sequence where each task sequence is assumed to carry similar weight. Set B is assigned with values according to their own sequence according to the condition written in methodology step 1.4 and step 1.5.

The two sets of parameters for task sequence, as shown in Table 3, are inserted into the tool and sensitivity analysis is carried out. Task step 3.1 to 3.4 is the group of tasks that can be planned in any order, whereas all the other tasks have to plan in order. 
Table 3. Case study with $\mathrm{Sq}=1$ and $\mathrm{Sq}=\{\mathrm{n}, \mathrm{n}-1, \ldots, 2,1\}$

\begin{tabular}{|c|l|c|c|}
\hline Level & \multicolumn{1}{|c|}{ Task Step } & $\begin{array}{c}\text { Set } \mathbf{A}, \\
\mathbf{S q}=\mathbf{1}\end{array}$ & $\begin{array}{c}\text { Set } \mathbf{B}, \mathbf{S q}=\mathbf{\text { n}}, \mathbf{n}- \\
\mathbf{1}, \ldots, \mathbf{2}, \mathbf{1}\}\end{array}$ \\
\hline 1st & $\begin{array}{l}\text { Ensure sea worthiness of } \\
\text { TEMPSC }\end{array}$ & 1 & 1 \\
\hline
\end{tabular}

\begin{tabular}{|l|l|c|c|}
\hline 2nd & $\begin{array}{l}1 \text { Ensure no damage to } \\
\text { exterior }\end{array}$ & 1 & 4 \\
\cline { 2 - 4 } & $\begin{array}{l}\text { 2 Ensure all maintenance } \\
\text { and gripe wires are } \\
\text { released }\end{array}$ & 1 & 3 \\
\cline { 2 - 4 } & 3 Check interior & 1 & 2 \\
\hline & 4 Start engine & 1 & 1 \\
\hline
\end{tabular}

\begin{tabular}{|l|l|c|c|}
\hline 3rd & $\begin{array}{l}3.1 \text { Ensure drain plug is } \\
\text { securely fitted }\end{array}$ & 1 & 6 \\
\cline { 2 - 4 } & $\begin{array}{l}3.2 \text { Ensure air support } \\
\text { system is operational }\end{array}$ & 1 & 6 \\
\cline { 2 - 4 } & $\begin{array}{l}3.3 \text { Ensure fuel level is } \\
\text { sufficient }\end{array}$ & 1 & 6 \\
\hline $\begin{array}{l}3.4 \text { Prepare waterspray } \\
\text { system for operation }\end{array}$ & $\begin{array}{l}\text { 3.5 Perform engine } \\
\text { checks }\end{array}$ & 2 \\
\hline $\begin{array}{l}3.6 \text { Engage full reverse } \\
\text { neutral RPM }\end{array}$ & 1 & 1 \\
\hline
\end{tabular}

From the result obtained, it is obvious that Set B has greater impact towards the overall score than the Set A, especially when the task that is in earlier sequence is accompanied with high severity. Parameter from Set B produced $71 \%$ more impact to the OS in the tool than Set A. If the group of tasks can either arrange in any sequence or conducted simultaneously as shown in Table 3 task step 3.1 to 3.4, it is acceptable to assign similar value for that particular group of tasks. However, for the tasks that have to plan in order, any error or failure when conducting prior task may either cause the tasks after not be able to carry out smoothly or unable to proceed at all, which proves that Set B is more reasonable and practical than Set A that assumed each task sequence to carry similar weight. Thus, it is justifiable to assign different values for the group of tasks that have to be conducted in sequence with the second parameter used in the sensitivity analysis, where prior task is assigned with higher value than the following task.

\subsubsection{Recovery}

As for recovery, two different parameters have been tested, where the first parameter is without considering recovery in the tool while the second parameter is takes in consideration of recovery. If all the recovery steps are not being considered, failure in accomplishing any task is assume to be irreversible and potentially resulted in their consequences respectively. This would lead to higher impact for tasks that can be recovered while reduce the impact for tasks that cannot be recovered with other actions towards the final assessment result, as shown in Smax value in Table 4.

Table 4. Case study without Incorporation of Recovery Steps

\begin{tabular}{|c|c|c|c|c|c|}
\hline Level & $\begin{array}{c}\text { Task Step } \\
\end{array}$ & Recovery Step & SR & $\mathbf{S q}$ & Smax \\
\hline $1 \mathrm{st}$ & Ensure sea worthiness of TEMPSC & Evacuation by other means & 27 & 1 & 27 \\
\hline \multirow[t]{4}{*}{ 2nd } & 1 Ensure no damage to exterior & Evacuation by other means & 27 & 4 & 108 \\
\hline & $\begin{array}{l}2 \text { Ensure all maintenance and gripe wires are } \\
\text { released }\end{array}$ & Evacuation by other means & 3 & 3 & 9 \\
\hline & 3 Check interior & No recovery available & 9 & 2 & 18 \\
\hline & 4 Start engine & Evacuation by other means & 3 & 1 & 3 \\
\hline \multirow[t]{6}{*}{$3 \mathrm{rd}$} & 3.1 Ensure drain plug is securely fitted & Evacuation by other means & 1 & 6 & 6 \\
\hline & 3.2 Ensure air support system is operational & No recovery available & 3 & 6 & 18 \\
\hline & 3.3 Ensure fuel level is sufficient & Evacuation by other means & 3 & 6 & 18 \\
\hline & 3.4 Prepare waterspray system for operation & No recovery available & 3 & 6 & 18 \\
\hline & 3.5 Perform engine checks & Evacuation by other means & 9 & 2 & 18 \\
\hline & 3.6 Engage full reverse neutral RPM & $\begin{array}{l}\text { Evacuation by other means } \\
\text { or Internal Recovery }\end{array}$ & 1 & 1 & 1 \\
\hline
\end{tabular}

In reality, errors in some of the tasks can be corrected with recovery actions. These recovery actions can amend those errors and the task can be completed successfully, which wouldn't result into any incident. Therefore, there should be differential on the values for tasks with recovery steps and without recovery steps, as shown in Table 5. The tasks that are unrecoverable should carries higher impact towards the final results than tasks that can be recovered with other actions. In order to develop a tool that is more realistic, the existence of recovery steps for each task are taken into consideration 
and incorporated into the ER2TC.

Table 5. Case study with Incorporation of Recovery Steps

\begin{tabular}{|c|c|c|c|c|c|c|}
\hline Level & Task Step & Recovery Step & SR & $\mathbf{S q}$ & $\mathbf{R}$ & Smax \\
\hline $1 \mathrm{st}$ & Ensure sea worthiness of TEMPSC & Evacuation by other means & 27 & 1 & 0.5 & 13.5 \\
\hline \multirow[t]{4}{*}{2 nd } & 1 Ensure no damage to exterior & Evacuation by other means & 27 & 4 & 0.5 & 54 \\
\hline & $\begin{array}{l}2 \text { Ensure all maintenance and gripe wires are } \\
\text { released }\end{array}$ & Evacuation by other means & 3 & 3 & 0.5 & 4.5 \\
\hline & 3 Check interior & No recovery available & 9 & 2 & 1 & 18 \\
\hline & 4 Start engine & Evacuation by other means & 3 & 1 & 0.5 & 1.5 \\
\hline
\end{tabular}

\begin{tabular}{|c|c|c|c|c|c|c|}
\hline \multirow[t]{6}{*}{$3 \mathrm{rd}$} & 3.1 Ensure drain plug is securely fitted & Evacuation by other means & 1 & 6 & 0.5 & 3 \\
\hline & 3.2 Ensure air support system is operational & No recovery available & 3 & 6 & 1 & 18 \\
\hline & 3.3 Ensure fuel level is sufficient & Evacuation by other means & 3 & 6 & 0.5 & 9 \\
\hline & 3.4 Prepare waterspray system for operation & No recovery available & 3 & 6 & 1 & 18 \\
\hline & 3.5 Perform engine checks & Evacuation by other means & 9 & 2 & 0.5 & 9 \\
\hline & 3.6 Engage full reverse neutral RPM & $\begin{array}{l}\text { Evacuation by other means } \\
\text { or Internal Recovery }\end{array}$ & 1 & 1 & 0.5 & 0.5 \\
\hline
\end{tabular}

In this research, ER2TC assessment tool is primarily designed to evaluate the competency level of each individual member of emergency response team in execution of safety critical tasks. However, the success of EER operations are also dependent on teamwork, collaboration from each team members and sometimes might even involves different parties to perform their respective tasks effectively. Nonetheless, the potential of ER2TC for adaptation and application in group assessment can be further explored.

\subsection{CONCLUSION}

Although competency management system is widely implemented by corporates in the oil and gas industry, however there is no detailed study on the assessment of technical skills in EER activities. In this paper, the capability of the ER2TC assessment tool in tackling and resolve the inadequacy as written in the literature review section is well addressed. Generally, the ER2TC assessment tool overcomes personal subjectivity and biasness of assessors, thus, producing reusable and reliable tool for decision makers in the evaluation of candidates. This tool has also implemented assumption on worst case scenario and stricter assessing criteria to evaluate the performance of candidates in EER activities. This is seen as necessary due to the critical nature and the must to ensure the successful for EER operations as any failure could potentially results in loss of lives. Thus, this ER2TC assessment tool has indeed sufficient to assess the technical skills of personnel in ensuring the success of EER operations in offshore installations.

\section{Acknowledgements}

The authors would like to thank Universiti Teknologi PETRONAS for providing the facilities.

\section{References}

[1] Cullen, L. W. D. 1993. The public inquiry into the Piper Alpha disaster. Drilling Contractor;(United States), 49.

[2] Deepwater Horizon Study Group. 2011. Final Report on the Investigation of the Macondo Well Blowout.

[3] Jones, M., and P. Bennett. 2015. Competent electrical staff-Are you sure they are competent?. Petroleum and Chemical Industry Committee Conference (PCIC), 2015 IEEE, 1-7.

[4] Jennings , M. 2016. Potential barriers to the competence assessment of Offshore Installation Managers: A hermeneutic perspective. Journal of Loss Prevention in the Process Industries, 44: 132-142.

[5] Mackenzie , C. F., J. Pasley, E. Garofalo, S. Shackelford, H. Chen, and N. Longinaker. 2017. Head-camera video recordings of trauma core competency procedures can evaluate surgical resident's technical performance as well as colocated evaluators. Journal of Trauma and Acute Care Surgery, 83: S124-S129.

[6] Naumann, F. L., S. Marshall, B. Shulruf, and P. D. Jones. 2016. Exploring examiner judgement of professional competence in rater based assessment. Advances in Health Sciences Education, 21: 775-788.

[7] Ponton-Carss, A., J. B. Kortbeek, and I. W. Ma. 2016. Assessment of technical and nontechnical skills in surgical residents. The American Journal of Surgery, 212: 1011-1019. 
[8] Koehler, R. J., S. Amsdell, E. A. Arendt, L. J. Bisson, J. P. Bramen, and A. Butler. 2013. The arthroscopic surgical skill evaluation tool (ASSET). The American Journal Of Sports Medicine, 41: 1229-1237.

[9] Wright, M., D. Turner, and C. Horbury. 2003. Competence Assessment For The Hazardous Industries. HSE Books.

[10] Brazier, A., P. Richardson, and D. Embrey. 1999. Human Factors Assessment Of Safety Critical Tasks. HSE Offshore Technology Report OTO 19990921999.

[11] Health, G. B., and S. Executive. 2017. The Control of Major Accident Hazards Regulations 2015: Guidance on Regulations. HSE Books.

[12] Occupational Safety and Health. 1995. A Handbook to the Control of Industrial Major Accident Hazards (CIMAH) Regulations 1996: Occupational Safety and Health Act 1994. Aliran Pusaka.

[13] Occupational Safety and Health. 2020. Occupational Safety and Health Act 1994 (Act 514) Regulations and Orders. International Law Book Services.

[14] Factories and Machinery. 2019. Factories and Machinery Act 1967 (Act 139), Regulations, Rules \& Orders. International Law Book Services.

[15] Reznick, R. K., and H. MacRae. 2006. Teaching surgical skills_changes in the wind. New England Journal of Medicine, 355 : $2664-2669$.

[16] Sanchez-Fernandez, J., J. Bachiller-Burgos, A. Serrano-Pascual, J. Cozar-Olmo, I. D.-G. Martín-Portugués, and F. Perez-Duarte. 2016. The assessment of surgical skills as a complement to the training method. Revision. Actas Urológicas Españolas (English Edition), 40: 55-63.

[17] Manca, D., S. Nazir, and S. Colombo. 2012. Performance indicators for training assessment of control-room operators. Chemical Engineering Transactions. 26: 285-290

[18] IADC. 2010. Health Safety and Environmental Case Guidelines for Mobile Offshore Drilling Units. International Association of Drilling Contractors.

[19] Wallace, I. G. 1993. The assessment of evacuation, escape and rescue provisions on offshore installations. Institution Of Chemical Engineers Symposium Series. 713-713.

[20] Skogdalen, J. E., J. Khorsandi, and J. E. Vinnem. 2012. Evacuation, escape, and rescue experiences from offshore accidents including the Deepwater Horizon. Journal Of Loss Prevention In The Process Industries, 25: 148-158.

[21] Guard, U. C.. 1983. Marine Casualty Report-Mobile Offshore Unit (MODU) OCEAN RANGER. Report USCG, 1.

[22] HSE. 1997. Prevention of Fire and Explosion, and Emergency Response on Offshore Installations. Health and Safety Executive Books.

[23] Norazahar, N., F. Khan, B. Veitch, and S. MacKinnon. 2014. Human and organizational factors assessment of the evacuation operation of BP Deepwater Horizon accident. Safety Science, 70: 41-49.

[24] Haddock, J. and M. Neill. 2001. CMAS-An innovative approach to offshore worker training \& competence management. Offshore Technology Conference.

[25] Karmous, K., N. Clyne, and I. McLean. 1998. Competency Assurance of Drilling Rig Operatives: A Drilling Contractors Approach. SPE International Conference on Health, Safety, and Environment in Oil and Gas Exploration and Production.

[26] OGP. 2010. Evacuation, Escape, and Rescue. The International Oil and Gas Producers.

[27] Standard, N. 2001. Risk and emergency preparedness analysis. Norwegian Technology Standards Insfitufion, Oslo, Norway.

[28] Mandal, S., K. Singh, R. Behera, S. Sahu, N. Raj, and J. Maiti. 2015. Human error identification and risk prioritization in overhead crane operations using HTA, SHERPA and fuzzy VIKOR method. Expert Systems with Applications,. 42: 7195-7206.

[29] Stanton, N. A. 2006. Hierarchical task analysis: Developments, applications, and extensions. Applied ergonomics, 37 : 55-79.

[30] Shepherd, A. 2000. Hierarchial Task Analysis. Taylor \& Francis.

[31] Kunlun, S., L. Yan, and X. Ming. 2011. A safety approach to predict human error in critical flight tasks. Procedia Engineering, 17: 52-62.

[32] Rose, J. A. and C. Bearman. 2012. Making effective use of task analysis to identify human factors issues in new rail technology. Applied Ergonomics, 43: 614-624.

[33] Baber, C. and N. A. Stanton. 2002. Task analysis for error identification: theory, method and validation. Theoretical Issues in Ergonomics Science, 3: 212-227.

[34] Doytchev, D. E. and G. Szwillus. 2009. Combining task analysis and fault tree analysis for accident and incident analysis: a case study from Bulgaria. Accident Analysis \& Prevention, 41: 1172-1179. 
Wen Khai Lim et al. /JEST-Journal of Energy and Safety Technology. vol. 4, no.1 (2021): 29-38

[35] Ainsworth, L. K. and B. Kirwan. 1992. A guide to task analysis. Taylor \& Francis.

[36] Center for Chemical Process Safety. 2011. Process safety leading and lagging metrics. AIChE, New York.

[37] Kennedy, B. 1993. A human factors analysis of evacuation, escape and rescue from offshore installations. Offshore Technology Report. 93: 994.

\begin{tabular}{|ll|}
\hline Nomenclature & \\
R & Recovery \\
SR & Severity Rating \\
Sq & Sequence \\
Smax & Max score for a particular task \\
TSmax & Total max score for all tasks \\
i & Task hierarchy level \\
S & Score obtained for a particular task \\
A & Action \\
TS & Total score obtained for all tasks [only consider tasks from similar level] \\
MF & Multiplying Factor \\
OS & Overall Score \\
\hline
\end{tabular}

